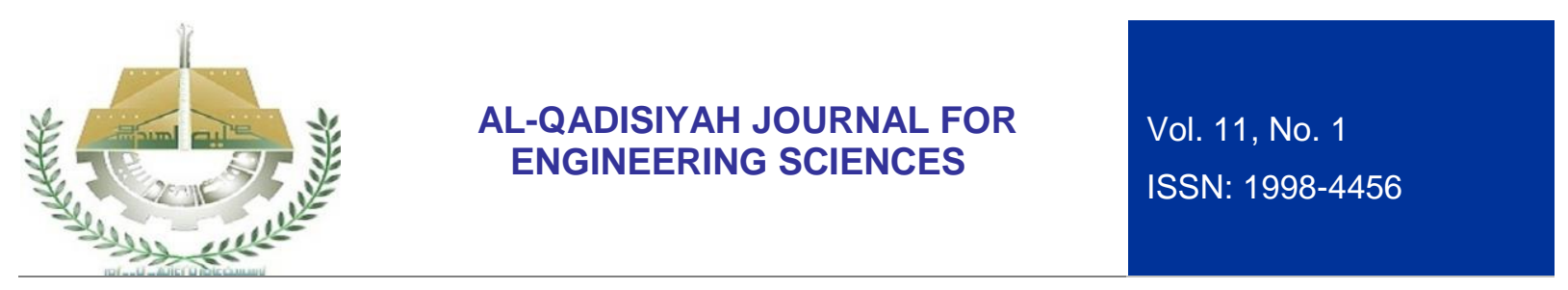

\title{
INVESTIGATION ON THE EFFECT OF THE POLYETHYLENE GLYCOL ON THE ELECTROPHORTIC DEPOSITION OF ALUMINA AND ZIRCONIA
}

\author{
Dr. Alaa Abdul hasan Atiyah, \\ University of Technology, Department of Materials Engineering, Baghdad. \\ E-mail: dralaadelta@gmial.com \\ Dr. Saad Badry Hasson Farid, \\ University of Technology, Department of Materials Engineering, Baghdad. \\ E-mail:Dr.saadbhf@gmail.com \\ Assist. Lec. Awham Jumah Salman , \\ Al-Furat Al-Awsat Technical University, Babylon Technical Institute, Babylon. \\ E-mail: awhamjumah@yahoo.com
}

Received on 23 October 2018 Accepted on 22 January 2018 Published on 14 May 2018 DOI: $10.30772 /$ qjes.v11i1.516

\begin{abstract}
This work is a study of the effect of polyethylene glycol (PEG) on electrophoretic deposition ( EPD) of alumina and zirconia particles. The effect of polyethylene glycol as a binder material and the toluene as a dielectric liquid, on the $\mathrm{pH}$ of suspension, the final thickness and green density of the deposed parts were studied. There was a difference in the behavior of polyethylene glycol when added for the alumina suspension and the zirconia suspension. The increase in polyethylene glycol was useful to deposit the zirconia more than alumina. The $\mathrm{pH}$ for both alumina and zirconia suspension increases with the increase of polyethylene glycol content and with the addition of toluene due to increase of the $\mathrm{OH}$ concentration in the suspension. This increase of $\mathrm{pH}$ enhances the particle surface charge and enhances the deposition rate, which led to the increase of density of the deposit.
\end{abstract}

Keywords: Electrophoretic deposition, Polyethylene glycol, Toluene, Alumina, zirconia, Green density.

\section{INTRODUCTION}

Electrophoretic deposition (EPD) has attracted a great deal of interest in recent years due to its wide range of coating and part forming applications. It can be applied to any fine powder in a colloidal suspension, including oxides, carbides, nitrides, metals, and polymers. Electrophoretic deposition (EPD) is proved as a powerful method for the formation of both uniform thin and thick films on substrates of complex geometry $[1,2,3]$. With EPD, ceramic bodies are shaped directly in 2012 from a stable colloidal suspension by a DC electric field, which causes the non metallic-surface charged particles to move and deposit on an oppositely charged 


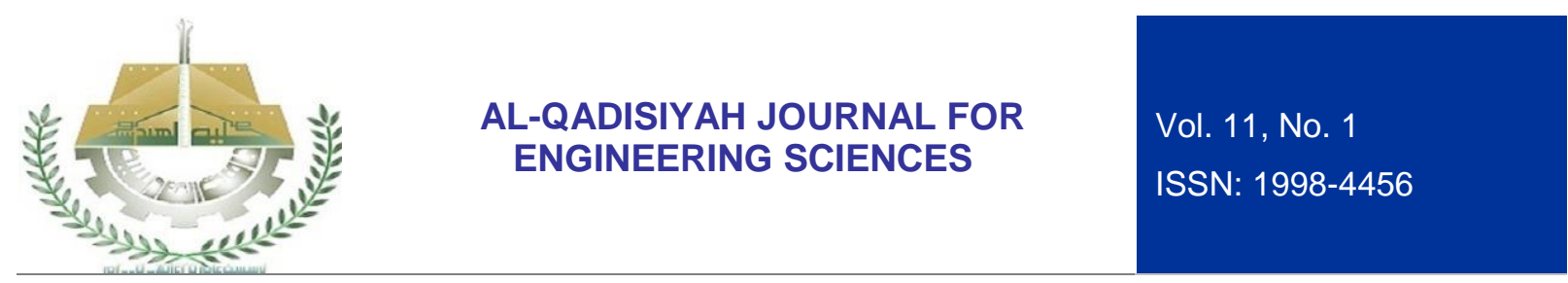

electrode $[4,5,6]$. Suspension preparation is a crucial step in this technique. It is very important to consider the solvent- dispersant - binder system, in terms of the solubility of binder and additives, the chemical compatibility of the components $[7,8]$. According to this, the EPD process requires the control of the suspension properties as well as the selection and optimization of the electrical parameters involved during forming [9].

Several papers have described the preparation of alumina or/and zirconia deposits by EPD. These studies focusing on the deposition rate and yield as a function of the process parameters; however, fewer is known about how the process parameters and the suspension composition and properties relate to the behavior of the deposit. It is well known that the packing density of ceramic green parts is of greatest importance in the production of advanced ceramics. For example, the particle packing density in green parts determines the sintering shrinkage, the density of the sintered ceramics, and the number of defects. In order to fully exploit the advantages of the EPD process, these elements that affect the structure of the green parts need to be better understood $[10,11]$.

In this work, the effect of the suspension's composition on the properties of the formed deposit layers is investigated. The goal was to determine the composition for effective and reproducible suspension for fabrication of alumina and zirconia parts, and hence to encourage industrialization of the process. The effect of polyethylene glycol in ethanolic suspensions was analyzed.

\section{MATERIALS AND METHODS}

\subsection{Materials Used}

The $\alpha-\mathrm{Al}_{2} \mathrm{O}_{3}$ (Hefei EV NANO Technology,Chain; particle size 20-30nm) powder and $3 \mathrm{~mol} \%_{2} \mathrm{Y}_{2} \mathrm{O}_{3}-$ $\mathrm{ZrO}_{2}$ (Hongwu International Group Ltd; Chain; average particle size 70-80 nm) powder were used for the synthesis of Alumina or zirconia samples. Ethanol (Scharlab S.L.,Spain) was used as the suspension medium. Polyethylene glycol 4000 (sinopharm chemical reagent Co.,Ltd ,Chain) was added to ethanol as a binder material and to enhance particle charging. Toluene (Avantor Performance Materials B.V., Germany) was also used to study suspension properties.

Ethanol-based suspensions for the production of dense samples were used. Ethylene glycol (PEG 4000) was added to the ethanol and must continue to mix by a magnetic stirrer (SH-2 model) to complete dissolve. Then the ceramic powder $(4 \mathrm{~g}$ for each $100 \mathrm{ml}$ ) was added to the solution and continues to mix in order to formation the suspension.

\subsection{Description of Electrophoretic Deposition Cell}

A power supply (H. T. model EISCO) was used as a DC supplier in the electrophoretic deposition process. The electrophoretic cell was a $100 \mathrm{ml}$ cylindrical glass beaker; and the electrodes were stainless steel $(316 \mathrm{~L})$ plate with dimensions $(2.5 \times 2 \times 0.1) \mathrm{cm}$, as show in Figure (1). The distance between the electrodes was $1.2 \mathrm{~cm}$. A variable voltage $(60-120 \mathrm{~V})$ is used in the course of the process, explicitly, the starting voltage was $60 \mathrm{~V}$ and increased by $10 \mathrm{~V}$ every 10 minutes, i.e. the total process time is 70 minutes. 

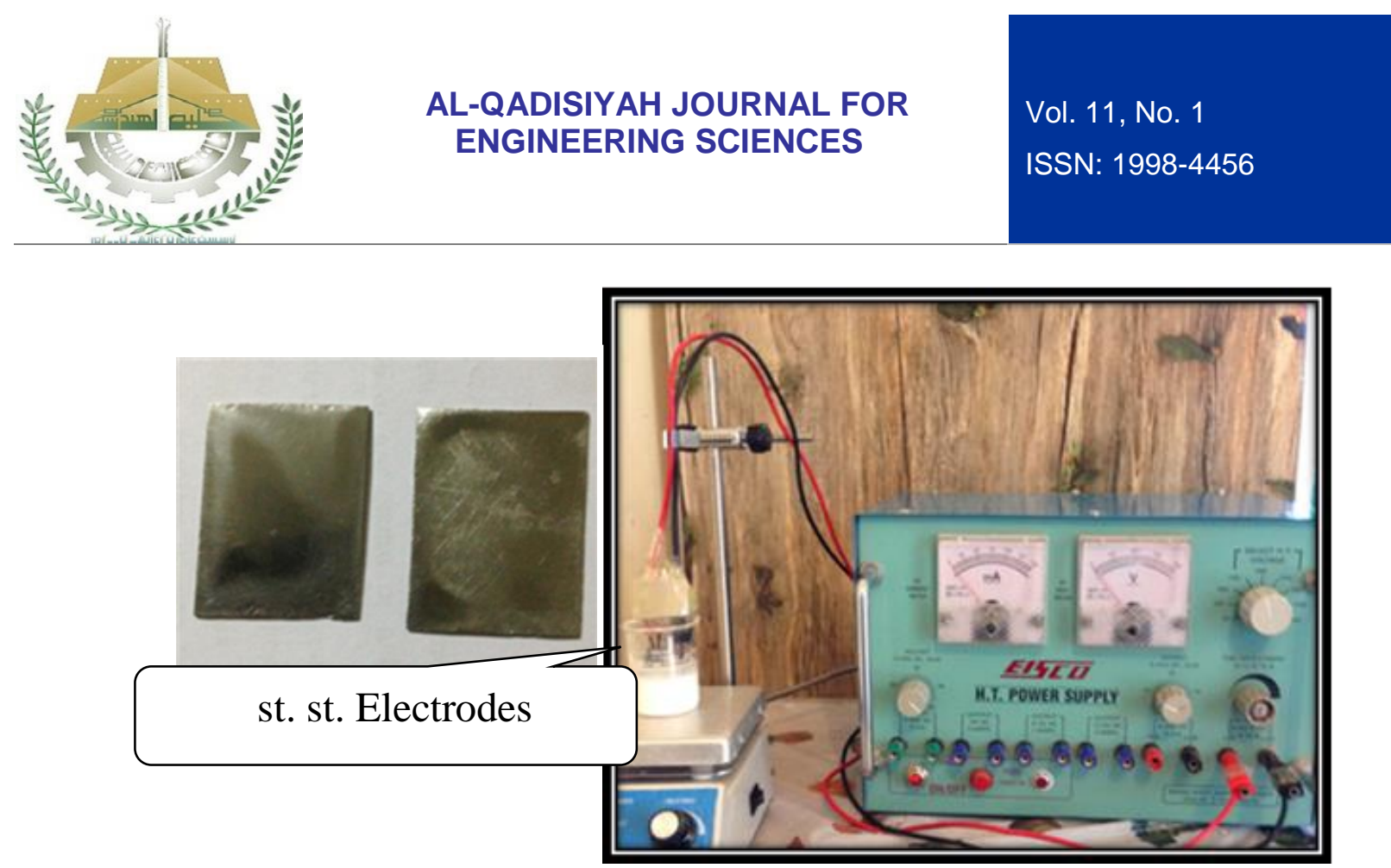

Figure 1: EPD set-up.

\subsection{Plan Work and Characteristics the Deposited Parts}

Two groups of alumina suspensions were prepared in this work in order to study the effect of the polyethylene glycol on green density and thickness of the deposited parts. The first group was a suspension of alumina in ethanol $(4 \mathrm{~g}$ for each $100 \mathrm{ml})$ and varied weights of PEG $(0,0.5,0.75,1) \mathrm{g}$. The second group was composed of a mixture of ethanol and $30 \%$ toluene with a varied weight of ethylene glycol $(0,0.5,0.75$ ,1) $\mathrm{g}$ for each $100 \mathrm{ml}$ of the mixture.

Also two groups of zirconia suspensions were prepared in order to study the effect of polyethylene glycol on the properties of zirconia parts. The first group was a suspension of zirconia in ethanol $4 \mathrm{~g}$ for each $100 \mathrm{ml})$ and varied weights of PEG $(0,1,1.5,2) \mathrm{g}$. the second group was composed of a mixture of ethanol and $30 \%$ toluene with varied weight of ethylene glycol $(0,1,1.5,2) \mathrm{g}$ for each $100 \mathrm{ml}$ of the mixture.

All dimension of the deposits were determined with a micrometer (TERMA,0-25 mm $/ 0.001 \mathrm{~mm}$ ).the weight of deposits were determined with a Digital Scale (DM.3,500g $\times 0.01 \mathrm{~g}$ ).

The weight of a unit volume of deposited part expressed in grams per cubic centimeter is the green density of the deposited part. It is calculated from dimensions evaluations and the weighting of deposited part as follows [12]:

$\rho_{g}=\frac{m_{g}}{V_{g}}$

Where $\left(\rho_{g}\right)$ green density $\left(\mathrm{g} / \mathrm{cm}^{3}\right),\left(m_{g}\right)$ green mass of the deposit $(\mathrm{g})$ and $\left(V_{g}\right)$ volume of the deposit $\left(\mathrm{cm}^{3}\right)$.

\section{RESULTS AND DISCUSSIONS}

\subsection{Study the Effect of an Applied Voltage}

Applying constant voltage (80V) in the electrophoretic process results in an alumina deposit and in an zirconia deposit with the formation of cracks after the drying process as seen in Figure (2-A). This result indicates low green density of the deposited parts. Applying higher voltages leads to uneven or irregular deposit. The low voltage is sufficient for low thicknesses but not when the thickness goes higher. 


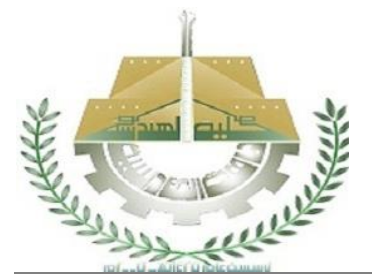

\section{AL-QADISIYAH JOURNAL FOR ENGINEERING SCIENCES}

Vol. 11 , No. 1

ISSN: $1998-4456$

On the other hand, starting with higher voltages results in fast, unsteady deposition process. Thus, it is decided to use an incremental increase of the applied the voltage as the thickness of the deposit increase (10V increase every $10 \mathrm{~min}$ ). This method of applying variable voltages is not preceded by other works as far as we know. The resulting deposit was free of cracks after the drying process; Figure (2-B) which indicates a homogeneous deposit with higher density.

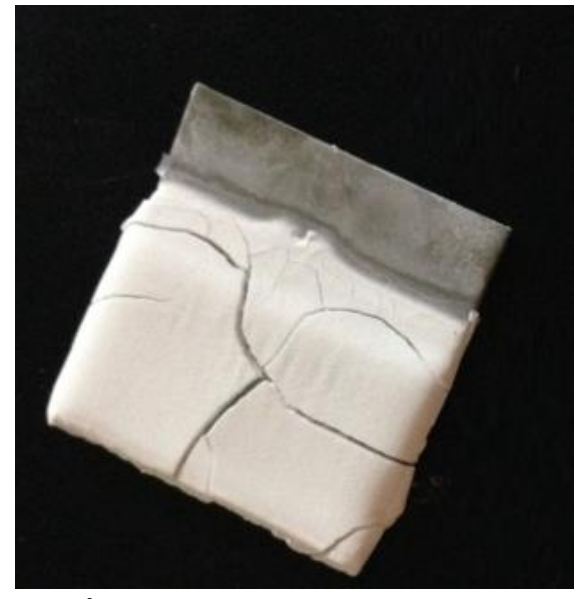

A-

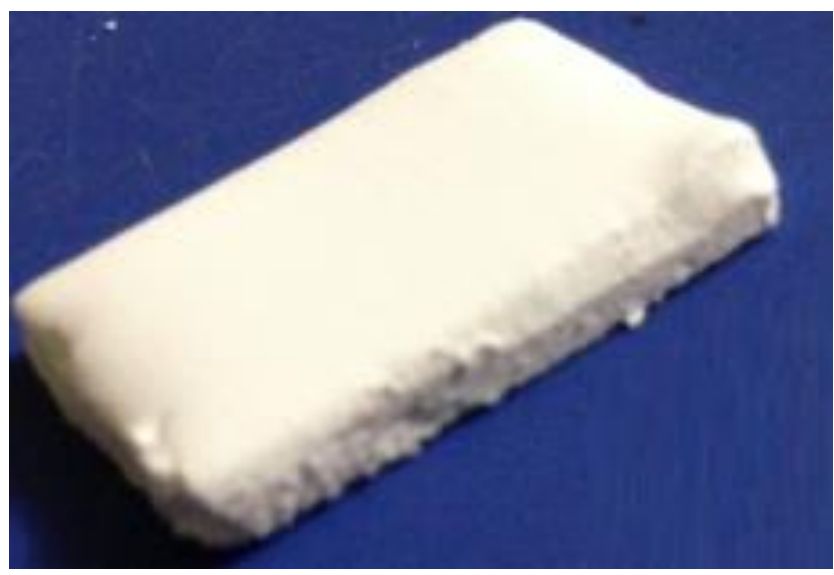

B-

Figure 2: Effect the type of DC voltage; A- constant voltage (80V), B- Variable voltages (60-120 V).

\subsection{Study the Electrophoretic Deposition of Alumina}

\subsubsection{The Effect of PEG Addition to the Suspension}

At first, the $\mathrm{pH}$ of the solution is monitored. It is found that the addition of PEG increases the $\mathrm{pH}$ of the suspension when dissolves, as shown in Figure (3) . I.e. the PEG increases the $\mathrm{OH}^{-}$concentration in the suspension. Thus, the PEG contributes in increasing the surface charge of the alumina particles in the suspension. Accordingly, the addition of the PEG is expected to enhance the density and the thickness of the alumina deposit.

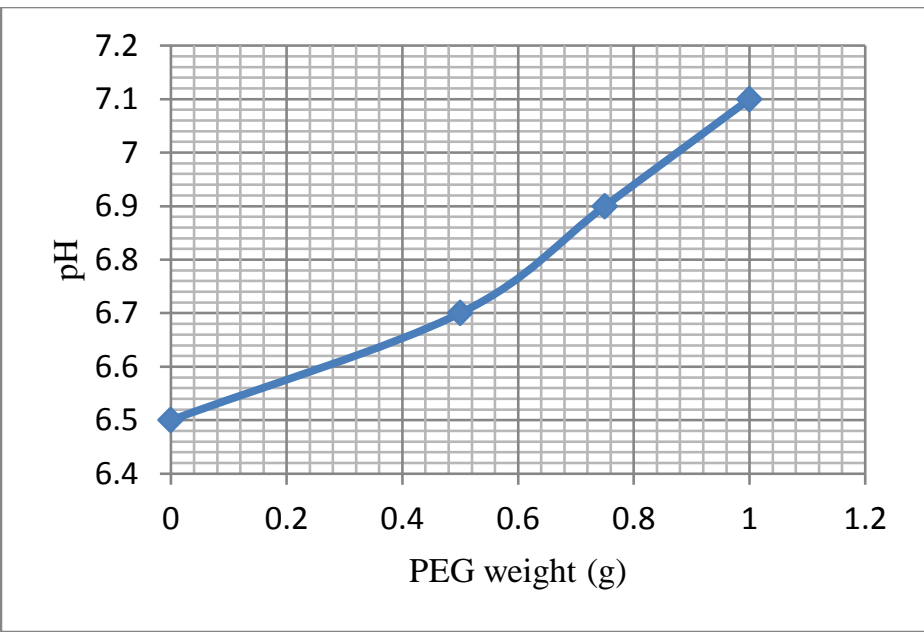

Figure 3: Effect of PEG on $\mathrm{pH}$ of ( $4 \mathrm{~g}$ alumina in $100 \mathrm{ml}$ ethanol) suspension. 


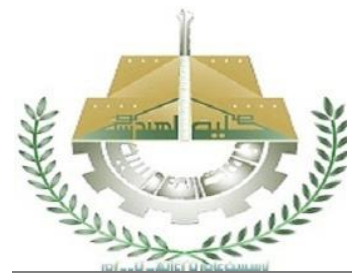

\section{AL-QADISIYAH JOURNAL FOR ENGINEERING SCIENCES}

Vol. 11 , No. 1

ISSN: 1998-4456

As shown in Figure (4-A), the density of deposit alumina was decreased with the increase the amount of PEG and reaches a minimum at $0.75 \mathrm{~g}$. For higher amounts of PEG, the density is increased due to increase discharge the particles. The thickness of the deposit, Figure (4-B) is increased with increasing PEG, i.e. it increased with the increasing amount of the suspended alumina. For PEG amount higher than $0.75 \mathrm{~g}$, the increased density led to lower thickness.

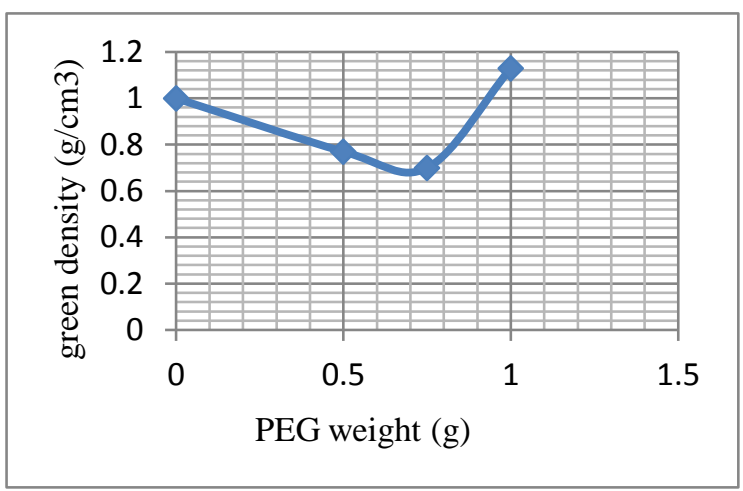

A- Green density

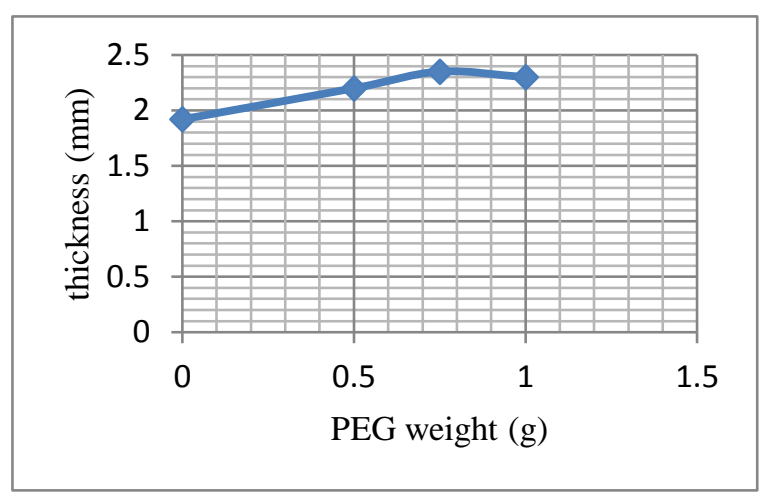

B- Thickness

Figure 4: Effect of PEG on thickness and green density of deposited alumina.

\subsubsection{Effect of $P E G$ addition to the ethanol-30\% toluene suspension}

The toluene was added to the ethanol in order to decrease the viscosity and dielectric constant of the suspension. The toluene also increases the $\mathrm{pH}$ of the suspension because the toluene increases the $\mathrm{OH}^{-}$concentration in the suspension. Figure (5) shows the increase of the $\mathrm{pH}$ of the suspension with the existence of $30 \%$ toluene, which is much higher than without it, as compared with that shown in Figure (3).

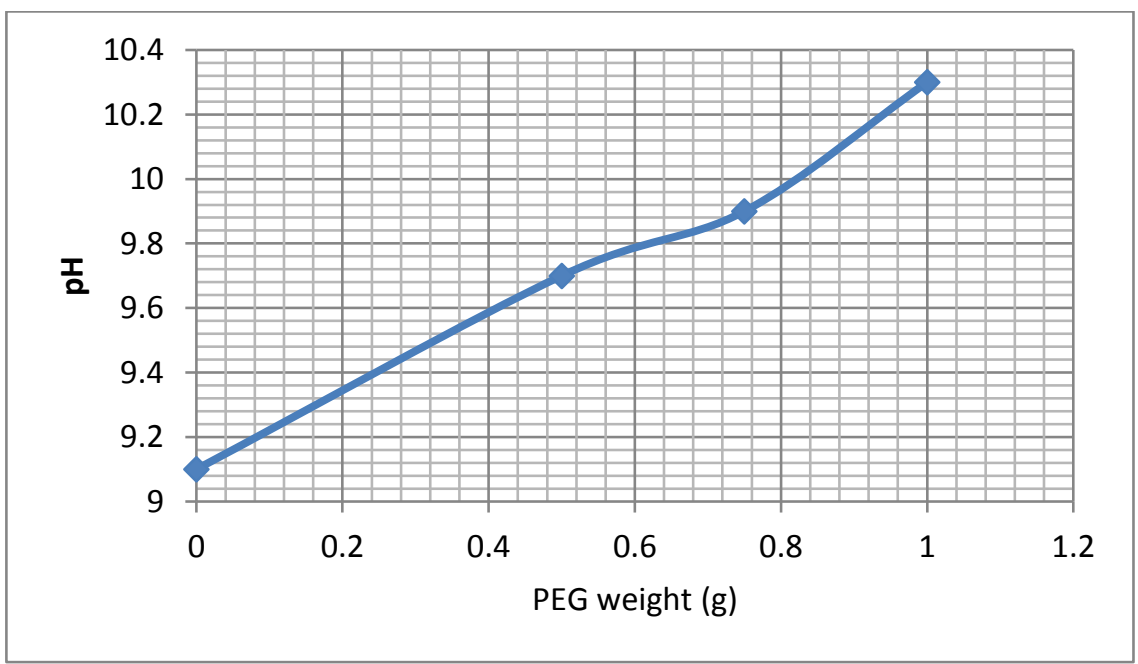

Figure 5: Effect of PEG addition on the $\mathrm{pH}$ of ethanol-30\% toluene suspensions.

The green density of deposited parted were increased with the ethanol-30\% toluene suspension of alumina and reached $1.25 \mathrm{~g} / \mathrm{cm}^{3}$, as shown in Figure (6-A). This result may be attributed to the higher $\mathrm{pH}$ of the suspension due to the including of the toluene and accompanied increase of the surface 


\section{AL-QADISIYAH JOURNAL FOR ENGINEERING SCIENCES}

Vol. 11 , No. 1

ISSN: 1998-4456

charges. When the amount of the PEG is increased from $0.75 \mathrm{~g}$ to $1.0 \mathrm{~g}$, it seems that the viscosity of the suspension is increased beyond the optimum and led to slowing down the particles mobility and accordingly, drops in the deposit density.

The thickness of deposit start at high value $(3 \mathrm{~mm})$ at zero PEG content compared with that of ethanol suspension alone $(1.92 \mathrm{~mm})$, as shown in Figure (6-B). Again, the increase of the particle surface charge enhances the deposition rate. The later drop in thickness for higher values of the PEG $(0.5$ and $0.75 \mathrm{~g})$ is due to increase of the density, i.e. due to the increase of packing of the deposit. Once more, the unhelpful increase of the viscosity of the suspension at PEG content of $1.0 \mathrm{~g}$ led to depress the deposition rate and the drop of both the density and the thickness of the deposit.

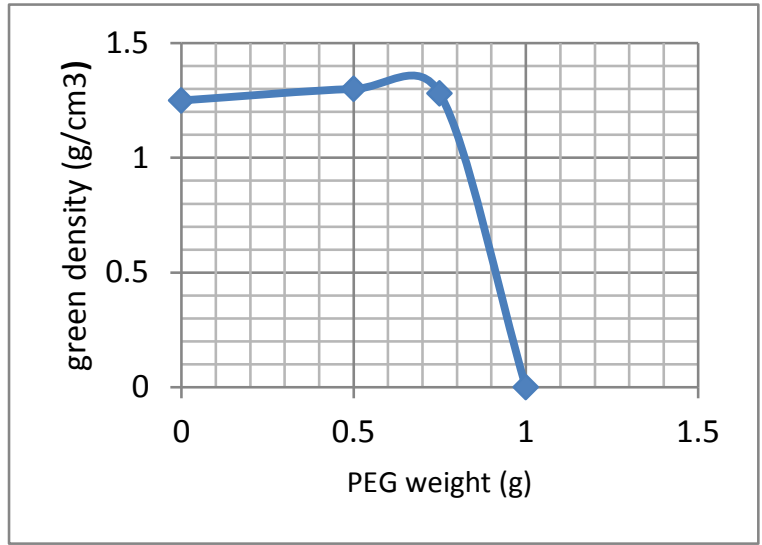

A- Green density

Figure 6: Effect of PEG on thickness and green density of alumina deposited from ethanol $-30 \%$ toluene suspensions.

\subsection{Study the Electrophoretic Deposition of Zirconia}

\subsubsection{The effect of PEG Addition to the Suspension}

At first, the $\mathrm{pH}$ of the solution is monitored. It is found that the addition of PEG increases the $\mathrm{pH}$ of the suspension, as shown in Figure (7). The PEG increases the $\mathrm{OH}^{-}$concentration in the suspension. Thus, the PEG contributes in increasing the surface charge of the zirconia particles in the suspension. Accordingly, the addition of the PEG is expected to enhance the density and the thickness of the zirconia deposit.

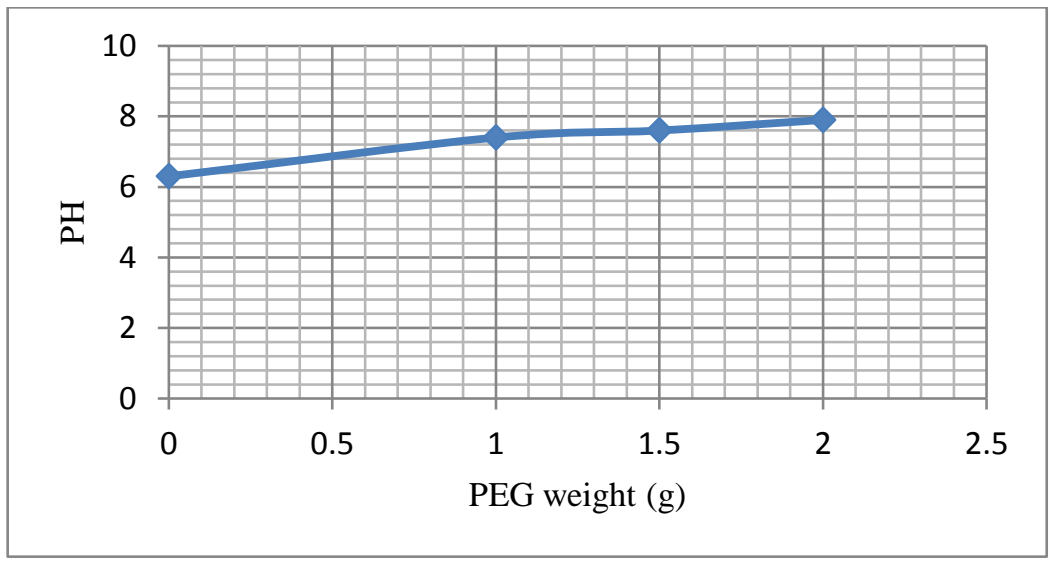

Figure 7: effect of $\mathrm{PEG}$ on $\mathrm{pH}$ of $4 \mathrm{~g}$ zirconia in $100 \mathrm{ml}$ ethanol suspension. 


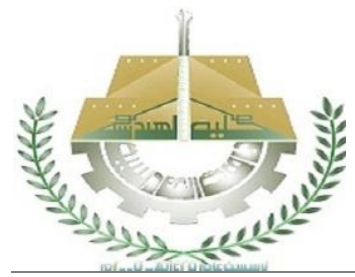

\section{AL-QADISIYAH JOURNAL FOR ENGINEERING SCIENCES}

Vol. 11 , No. 1

ISSN: 1998-4456

As shown in Figure (8-A), the density of deposited zirconia was increase with the increase the amount of PEG, this increase is due to the increased particle charge in the suspension. For increase amount of PEG, the thickness is decreased. This decrease in thickness occurs due to the increase the packed of deposit with increase the amount of PEG. The thickness of the deposit, Figure (8-B) is decreased with increasing PEG.

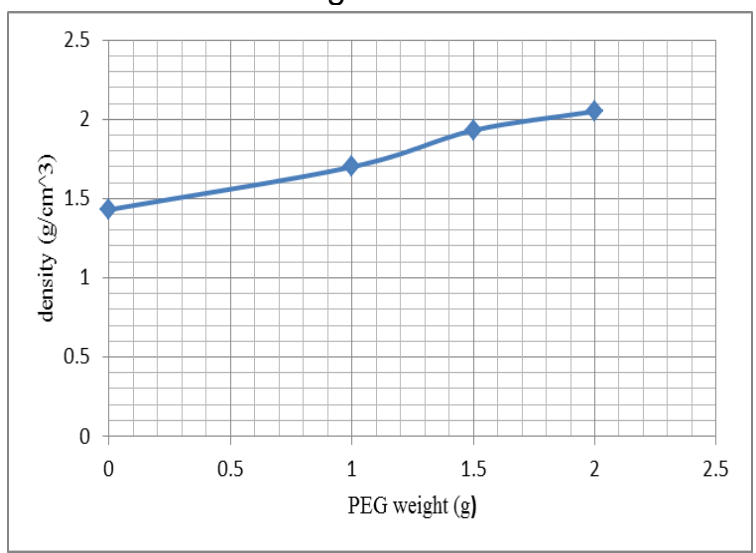

A-Green density

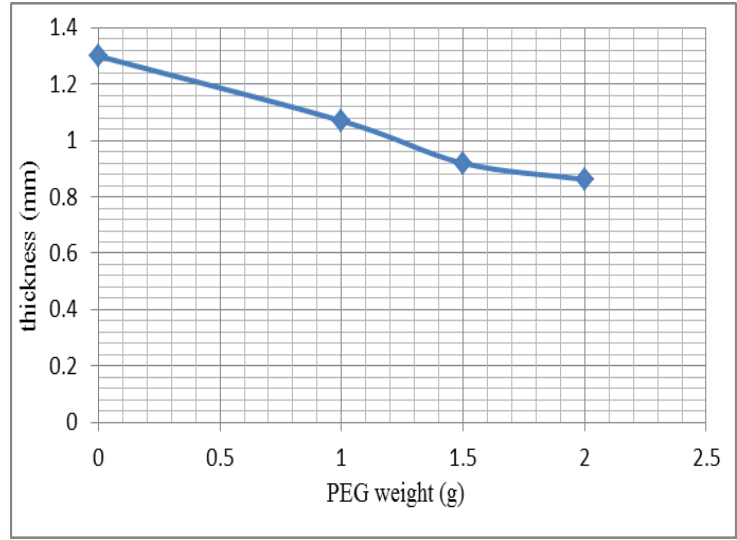

B-Thickness

Figure 8: effect of PEG on thickness and green density of deposited zirconia from $4 \mathrm{~g}$ zirconia in $100 \mathrm{ml}$ ethanol suspension.

\subsubsection{Effect of PEG Addition to the Ethanol-30\% Toluene Suspension}

Figure (9) shows the increase of the $\mathrm{pH}$ of the suspension with the existence of $30 \%$ toluene, which is much higher than without it, as compared with that shown in Figure (7). This increase in the $\mathrm{pH}$ was due to the toluene increased the $\mathrm{OH}^{-}$concentration in the suspension.

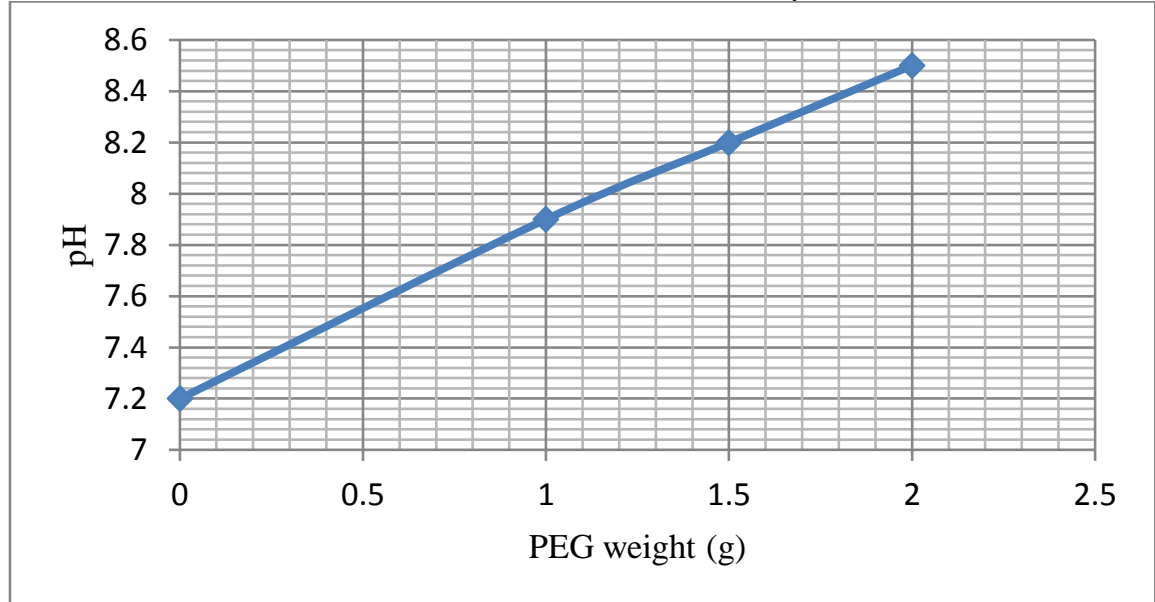

Figure 9: Effect of PEG addition on the $\mathrm{pH}$ of ethanol-30\% toluene suspensions.

As shown in Figure (10-A), in ethanol-30\% toluene suspension, the density of deposited zirconia was increase with the increase the amount of PEG, this increase is due to the increased particle charge in the suspension. The increase in density of the deposited parts from ethanol- $30 \%$ toluene suspensions comparted with deposited parts from the ethanol suspensions were due to the toluene increases the particle charge in the suspension. 


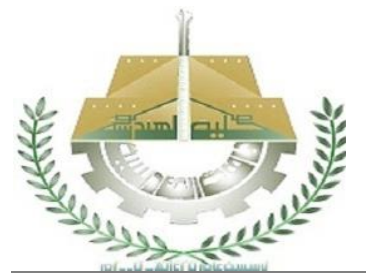

\section{AL-QADISIYAH JOURNAL FOR ENGINEERING SCIENCES}

Vol. 11, No. 1

ISSN: 1998-4456

For increase amount of PEG, the thickness is decreased. This decrease in thickness occurs due to the increase the packed of deposit with increase the amount of PEG. The thickness of the deposit, Figure (10-B) is decreased with increasing PEG.

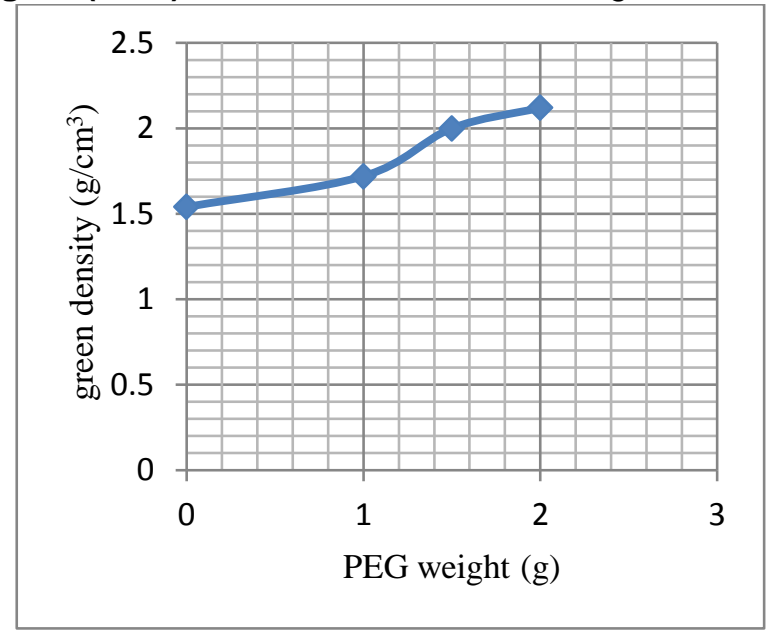

A- Green density

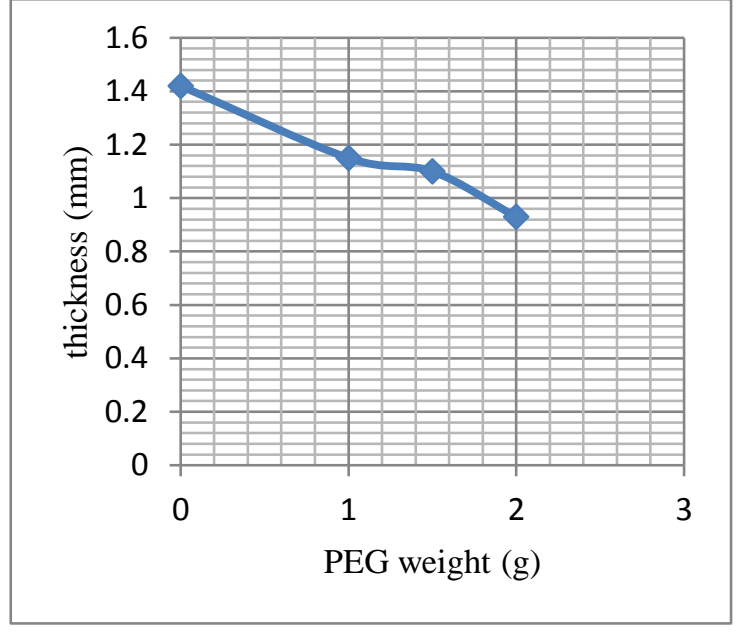

B- Thickness

Figure 10: Effect of PEG on thickness and green density of zirconia deposited from ethanol $-30 \%$ toluene suspensions.

\section{CONCLUSION}

1- The $\mathrm{pH}$ of the suspension increase with the increase of PEG content and with the addition of toluene due to increase the $\mathrm{OH}^{-}$concentration in the suspension. Sometimes, this increase of $\mathrm{pH}$ enhances the particle surface charge and enhances the deposition rate, which led to the increase of density of the deposit.

2- In ethanol suspension, the increase in content of PEG cause of decreasing in the density of alumina deposited parts due to the increase in the viscosity of suspension. In ethanol- $30 \%$ toluene suspension, the exaggerated content of PEG in alumina suspension (beyond $0.75 \mathrm{~g}$ ) led to increase the $\mathrm{pH}$ and decrease the dielectric constant of the suspension with negative effect on the deposition rate.

3- With regard to zirconia, the increase in the quantity of polyethylene glycol has had a good effect on the deposition rate because of the high dielectric constant of zirconia powder compared with the alumina powder.

4- Both the deposit thickness and density increase with the increase of the deposition rate and reach an inflection point where the increase in density led to higher particle packing and thus, reduced deposit thickness. 


\section{REFERENCE}

1. Atsushi Nakahira ; Fumihide Nishimura, "Green Fabrication of Porous Ceramics Using an Aqueous Electrophoretic Deposition Process ",Communications of the American Ceramic Society, Vol. 86, No. 7, 2003,pp.( 1230-1232).

2. MARIJAS. LAZI; KORNELIJA SIMOVI; VESNA B. MISKOVIC-STANKOVI C ; DUSAN KICEVIC, " The influence of the deposition parameters on the porosity of thin alumina films on steel", J.Serb.Chem.Soc., Vol.69,No.(3) , 2004,pp.(239-249).

3. Vesna Mišković-Stanković, " ELECTROPHORETIC DEPOSITION OF ALUMINA AND BOEHMITE COATINGS ON METAL SURFACES", Macedonian Journal of Chemistry and Chemical Engineering, Vol. 31, No. 2,2012, pp. (183-193).

4. Linda Berg Aas, " Corrosion protection of metals/alloys by EPD (electrophoretic deposition)", Master thesis ,Norwegian University of Science and Technology, Department of Materials Science and Engineering ,2014.

5. Pouya Amrollahi; Jerzy S. Krasinski; Ranji Vaidyanathan; Lobat Tayebi;Daryoosh Vashaee, "Electrophoretic Deposition (EPD): Fundamentals and Applications from Nano- to Micro-Scale Structures", Handbook of Nanoelectrochemistry, Springer International Publishing Switzerland,2015.

6. E. Caproni ; D. Gouvea ; R. Muccillo, "Yttria-stabilized zirconia closed end tubes prepared by electrophoretic deposition”, Science Direct ,Ceramics International ,Vol.37, 2011 ,pp.(273-277).

7. Laxmidhar Besra ; Meilin, "A review on fundamentals and applications of electrophoretic deposition (EPD)", Science Direct, Progress in Materials Science,Vol. 52, 2007 ,pp.(1-61) Liu.

8. Shaohua ZHANG ; C.C.Sorrel and F.Y.Li, "Electrophoretic Deposition of Ceramic Powder",J.Mater. Sci. Tehnol., Vol.21, 2005 , pp.(107-110).

9. B. Ferrari; R. Moreno, "Electrophoretic Deposition of Aqueous Alumina Slips" ,Journal of the European Ceramic Society, Vol. 17,1997,pp.(549-556).

10. Sasa Novak; Katja Konig, "Fabrication of alumina parts by electrophoretic deposition from ethanol and aqueous suspensions", Science Direct ,Ceramics International ,Vol.35, 2009,pp.( 2823-2829).

11. Eduardo Antonelli; Ronaldo Santos da Silva; Maria Inês Basso Bernardi ; Antonio Carlos Hernandes, "Electrophoretic Deposition of BaTi 0.85 Zr0.15O3 Nanopowders", Materials Research,Vol. 16, No. 6,2013,pp.(1344-134).

12. Goupee, A, "Methodology for the Themomechanical Simulation and Optimization of Functionally Graded Materials", M. Sc. Thesis, Mechanical Engineering,2005, p. (6). 